\title{
A BALANCED THERMOCOUPLE AND FILTER METHOD OF ULTRA-VIOLET RADIOMETRY, WITH PRACTICAL APPLICATIONS
}

\author{
By W. W. Coblentz, R. Stair, and J. M. Hogue
}

\section{ABSTRACT}

This paper is a further contribution (see RP318) to the investigation of filter radiometry, as applied to the measurement of ultra-violet radiation used for therapeutic purposes.

The experimental procedure consisted in exposing both receivers of a thermocouple simultaneously to radiation. On covering one receiver with a filter that excludes the ultra-violet, and the other receiver with a window that freely transmits these ultra-violet rays and exactly balances the transmission losses of the exclusion filter, throughout the remaining part of the spectrum, the galvanometer deflection obtained on exposure of the two thermocouple receivers to the source is a direct measurement of the ultra-violet emitted.

Data are given on the amount of ultra-violet in sunlight at midday in summer and in winter in Washington.

An experimental procedure is described for testing the performance and for the standardization of photo-electric cells, for use as ultra-violet dosage meters; also for using measured amounts of ultra-violet in physiological experiments using spectrally homogeneous ("monochromatic") and heterogeneous ultraviolet radiation.

\section{CONTENTS}

I. Introduction

II. Apparatus and methods of observation

1. The balanced thermocouples.

2. The filters

(a) The exclusion filter

(b) Exclusion filter corrections.... 729

(c) Comparison of a cell of water and a thick plate of quartz for excluding the infra-red.....

3. Calibration of the thermocouple

4. Experimental procedure

III. Reduction of observations on ultra-violet solar radiation ........ 732

1. Reduction of data obtained by Method I

2. Reduction of data obtained by Method II

IV. Integration of ultra-violet radiation by spectroradiometric and by

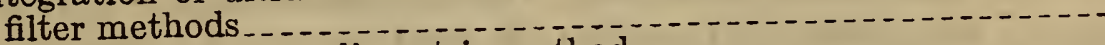

1. The spectroradiometric method ..........................

2. The balanced thermopile and exclusion filter method......

V. Calibration of a photo-electric cell in absolute units by radiometric filter methods........

VI. Physiological tests.............

VII. Summary ......

VIII. Bibliography 


\section{INTRODUCTION}

The balanced thermocouple method of measuring ultra-violet radiation was described in a previous paper (1). ${ }^{1}$ The method is based upon the simple physical principle that when both receivers are simultaneously exposed to the sun, or to a uniform flux of radiation from an artificial source, practically no electric current flows through the galvanometer-it is "balanced" radiometrically.

On covering one receiver with a filter (for example, of barium flint glass) that excludes the ultra-violet which it is desired to measure, and the other receiver with a window (for example, crystalline quartz or, Corex G980A glass) that freely transmits the ultra-violet, and has the same transmissive properties as the exclusion filter for the remaining part of the spectrum, the galvanometer deflection obtained on exposure of the two thermocouple receivers through this combination of filters is a direct measure of the ultra-violet emitted by the source under investigation.

This method was considered a year or so ago; but only recently was it given a thorough trial, the results of which are reported in this paper.

The most difficult problem that has confronted radiometricians in recent years is the exact evaluation of ultra-violet radiation, particularly of wave lengths less than $313 \mathrm{~m} \mu$ (millimicrons, $3,130 \mathrm{~A}$ ), recognized by biologists as having a specific healing value, particularly in preventing rickets.

The logical procedure would be to place the source at a known distance from the entrance slit of a spectroradiometer and measure the spectral intensity of the radiation emitted.

Correcting these spectral radiation intensities for absorption losses in the spectroradiometer gives the intensities incident upon the entrance slit, and hence, the intensity (the radiant flux) at a given distance from the lamp. Recent measurements by this method have been described by Barnes (2).

This method requires an exact knowledge of the size of the entrance and the exit slits, and of the transmission losses in the spectroradiometer, including the losses in the window (if any is used) of the thermopile or other radiometer receiver. The spectrometer slits being small (only about 5 by $0.5 \mathrm{~mm}$ ) large errors may be introduced. The lens material, whether of fluorite or of fused quartz, absorbs some of the short wave length ultra-violet. Hence, if the absorption in the spectroradiometer has been determined, using a uniform irradiation over the whole lens, then it will be necessary to irradiate the whole lens uniformly with the source under investigation. This is impracticable in an investigation of an extended source; for example, a carbon arc lamp in a large reflector, or a small mercury arc in a quartz bulb, in which the lamp is so placed that both the bulb and the arc irradiate the lenses and the prism. In the latter source only about 5 per cent of the total ultra-violet is contributed by reflection and scattering by the outer portion of the bulb.

Unless the investigator can have the transmission of his spectroradiometer determined in another laboratory, he is obliged to have an extra monochromator to isolate the spectral lines used in deter-

\footnotetext{
1 Figures in parenthesis here, and throughout the text indicate references given in the bibliography at the end of this paper.
} 
mining the absorption in his spectroradiometer. In view of the scarcity of lens and prism material, and the difficulty in using such apparatus, particularly on extended sources, substitute methods are urgently needed.

In this connection filter methods (1) using a nonselective (thermopile) radiometer appear promising in view of the fact that the receiver does not deteriorate on exposure to ultra-violet radiation (5), and it can be easily calibrated in absolute units by exposure to a standard of radiation (3).

As will be shown presently the filter radiometer offers a ready means of calibrating a photo-electric radiometer in absolute value, and thus provides a convenient dosage meter of ultra-violet radiation.

In connection with the balanced thermocouple and exclusion filter method of radiometry the spectroradiometer is used as a secondary instrument to obtain the approximate spectral energy distribution of the source, which information is necessary in order to obtain the conversion factors for each type of source; for example, the sun, the mercury arc, etc. However, from the limited number of lamps examined, of a given type (for example, the tungsten mercury arc lamp in a quartz bulb) the conversion factor is a constant value; hence, lamps can be tested on a large scale of production by the filter method, while only a relatively limited number can be tested by the tedious spectroradiometric method. Laboratories which do not possess ultra-violet spectroradiometers can calibrate their filter radiometers by interchange of ultra-violet lamps or by having the radiometer calibrated in some laboratory possessing complete equipment.

\section{APPARATUS AND METHODS OF OBSERVATION}

The writers have always adhered to the policy of using the simplest and least complicated auxiliary apparatus in connection with the radiometer. Electron-tube amplifying devices have been tried and automatic recording apparatus has been considered; but since these devices increase the complexity of the procedure without markedly increasing the precision of the measurements the writers use a wellshielded, quick-acting, ironclad Thomson (4) (or a quick-acting d'Arsonval) galvanometer. The Thomson galvanometer is far more sensitive than required, but by inserting 500 to $30,000 \mathrm{ohms}$ in series, it is readily adapted for measuring either intense or weak sources of ultra-violet radiation.

Aside from occasional disturbances by radio waves which happen to tune into the thermopile circuit, the writers are favorably situated as regards mechanical and electromagnetic disturbances and hence, can control their measurements more easily than workers less favorably situated.

\section{THE BALANCED THERMOCOUPLES}

The thermocouple is a simple device mounted upon an insulated base as indicated in Figure $1, B$ and $E$. The rear of the thermocouple container, $E$, is painted with lampblack, which absorbs the radiation entering through the openings surrounding the receivers, and, by scattering and reradiation, assists in establishing uniform temperature conditions within the container. As described in the previous paper 
(1) the latter is wrapped in white cotton batting in order to prevent heating in sunlight.

The thermocouples used consisted of copper and bismuth wire (the latter $0.1 \mathrm{~mm}$ in diameter, pressed flat) or copper and constantan ("Advance," No. 40, thickness $0.075 \mathrm{~mm}$ ) wire rolled flat, and having a thickness of $0.018 \mathrm{~mm}$. The copper wire has a thickness of $0.037 \mathrm{~mm}$. The receivers are of pure tin; thickness $0.018 \mathrm{~mm}$; bright on the rear, and painted with lampblack, then smoked, on the front surface. For further details concerning construction, reference is made to earlier papers (6).

The distance between the receivers is determined by the size of the water cell used in front of the thermocouple, and also by the fact that, if the two junctions are too widely separated, there may be difficulty in maintaining uniformity of temperature conditions within the container, which determines the steadiness of the zero reading of the
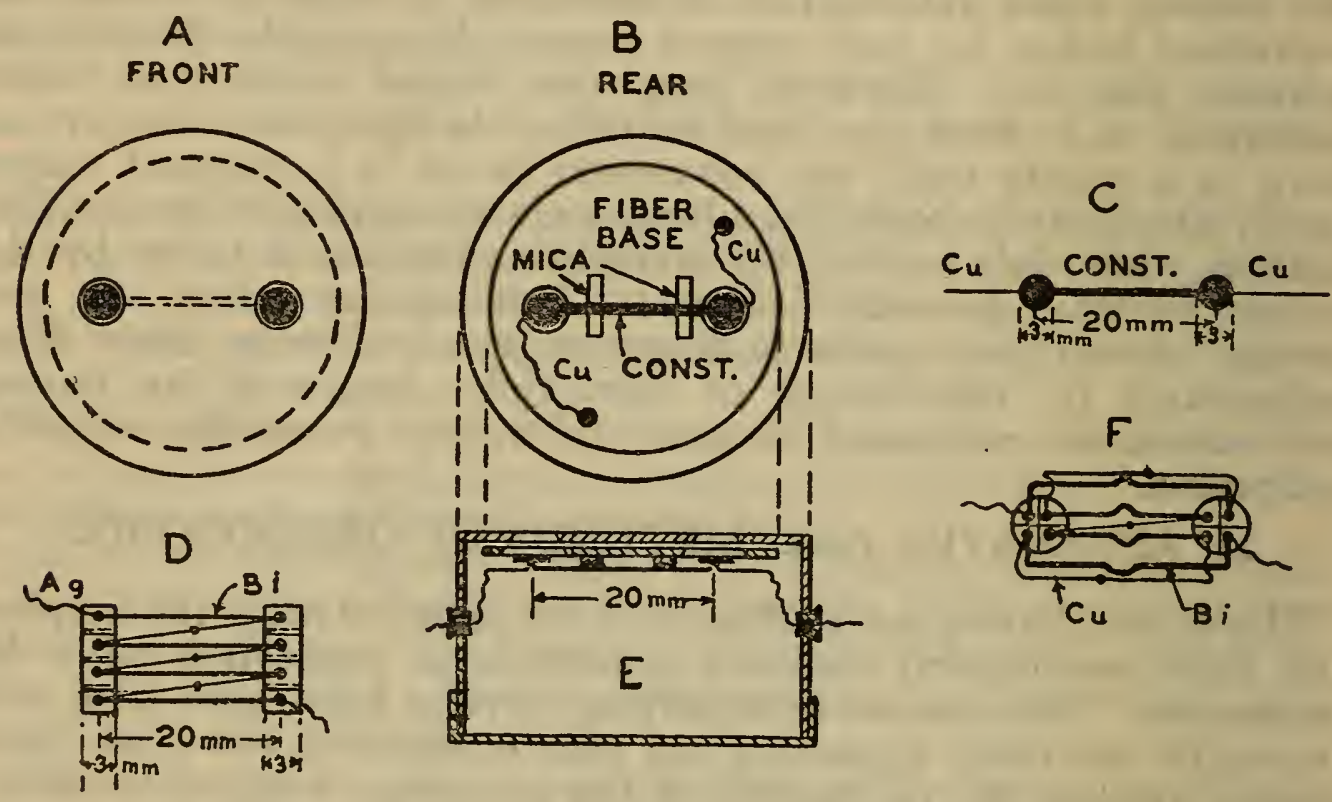

FIGURE 1.-Thermocouple mounting, also designs of thermopiles

galvanometer or other indicating device. The experimental data reported in this paper were obtained on thermocouples in which the centers of the receivers were separated by $18 \mathrm{~mm}$. As indicated in Figure 1, a separation of 20 to $25 \mathrm{~mm}$ should prove satisfactory.

A separation of 30 to $40 \mathrm{~mm}$ between the centers of the receivers would permit the use of larger filters of barium flint and quartz, as illustrated in Figure 2, $A$, thus increasing the ability to keep them free from dust. But this increases the expense of the water cell, and may decrease the temperature uniformity within the thermocouple container.

Using widely separated receivers requires two window covers of fluorite (or quartz) instead of a single window as used in the present work.

Using the single thermocouple receiver and filter method previously employed (1), comparisons were made of the accuracy of various forms of balanced thermocouples (fig. $1, C$ ) in measuring the ultraviolet in sunlight. 
Thermocouple No. 233 of copper constantan, having a resistance of $2.6 \mathrm{ohms}$ and receivers $3 \mathrm{~mm}$ in diameter, blackened on front and rear, was used in a mounting with windows $3.3 \mathrm{~mm}$ in diameter. Thermocouple No. 234 of copper constantan with receivers $3 \mathrm{~mm}$ in diameter, painted black on the front, and left unpainted on the rear, was tested in an inclosure having, first, the window openings $3.3 \mathrm{~mm}$, and then with openings $3.5 \mathrm{~mm}$ in diameter, to determine the effect of heating the interior by direct solar radiation. No unequal heating of the interior that was attributable to the larger window was observed.

Thermopile No. 235, consisting of four junctions, of bismuthcopper, and having a resistance of 12.3 ohms, was constructed as indicated in Figure 1, $F$. The receivers were about $5 \mathrm{~mm}$ in diameter. It was tested back of window openings that were a little less than 5 $\mathrm{mm}$ in diameter in order to prevent solar radiation from entering the rear of the inclosure. It was tested also with the windows $5.7 \mathrm{~mm}$ in diameter.

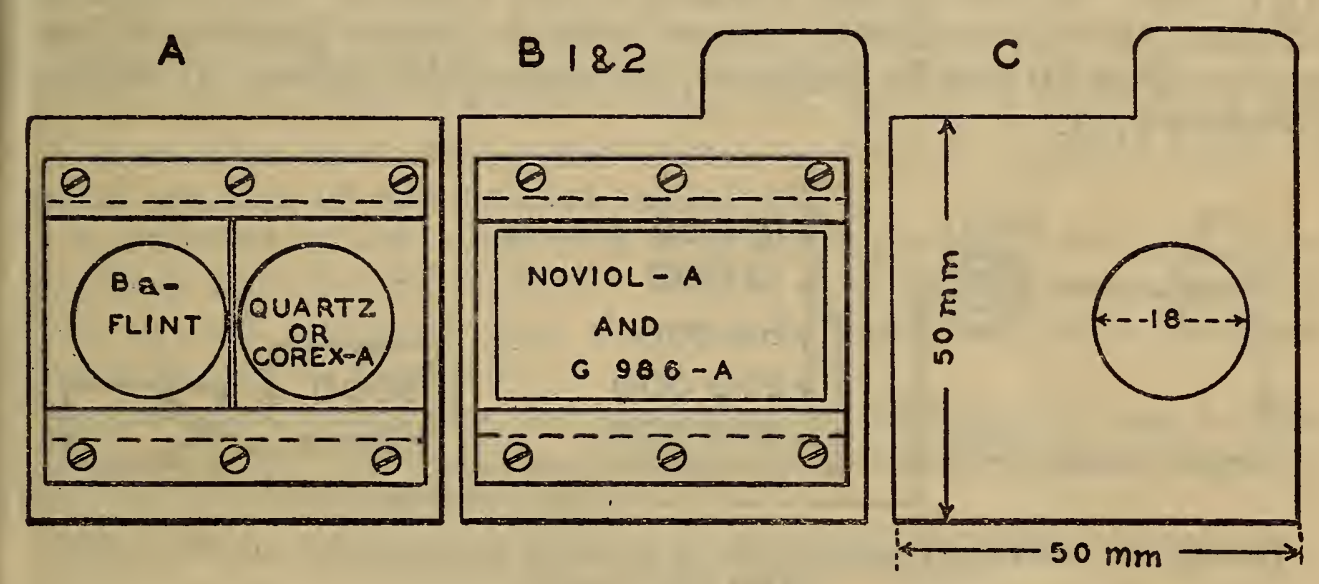

FIGURE 2.-Filter mountings

Aside from the fact that when the window opening was larger than the radiometer receiver, less refinement was required in exposing the instrument to the sun, within the errors of observation, no appreciable difference was found in the measurements made with the various arrangements of the radiometer receivers and sizes of windows.

The use of a 4-junction thermopile as depicted in Figure 1, F, increased the radiation sensitivity about eightfold. This is useful for measuring weak sources of ultra-violet radiation, but it is too sensitive for use in measuring solar radiation without $1,000 \mathrm{ohms}$ resistance in the Thomson galvanometer circuit.

Another form of balanced thermopile arrangement is depicted in Figure $1, D$. It was used in measuring the radiation from the solar corona (7).

As already mentioned, the trial of this type of radiometer was delayed owing to the fear that exposure of the device to a source so intense as the sun would introduce unsteadiness. It was, therefore, an agreeable surprise to find that, although a small difference in the radiation sensitivity of the two thermopile receivers produced a permanent zero shift of 1 to $15 \mathrm{~cm}$ of the galvanometer reading, there was little or no shifting of the zero while making the readings.

$$
74280-31-8
$$


To eliminate the error that may result from this zero shift a small current from a dry battery is maintained through the galvanometer circuit, in a direction opposite to that causing the zero shift, and of sufficient strength to maintain the same zero reading when making the measurements on the sun and when calibrating the thermopile against the standard of radiation (3). This arrangement is depicted in Figure 3. It is easily assembled by employing resistors in common use in radio installations.

\section{THE FILTERS}

The balanced thermopile method of ultra-violet filter radiometry was tested by two methods:

1. The front of the thermopile container (fig. 1, A) was covered with cell of water, $1 \mathrm{~cm}$ in thickness, and $3 \mathrm{~cm}$ in diameter, with windows of crystal quartz about $3 \mathrm{~mm}$ in thickness, attached to the glass container by means of Chatterton wax, or Picein, melted around the outer edge. To reduce the heating of the water by the intense solar radiation, the water cell was covered with an opaque diaphragm having two openings $10 \mathrm{~mm}$ in diameter, symmetrically placed, as indicated in Figure 2, $A$.

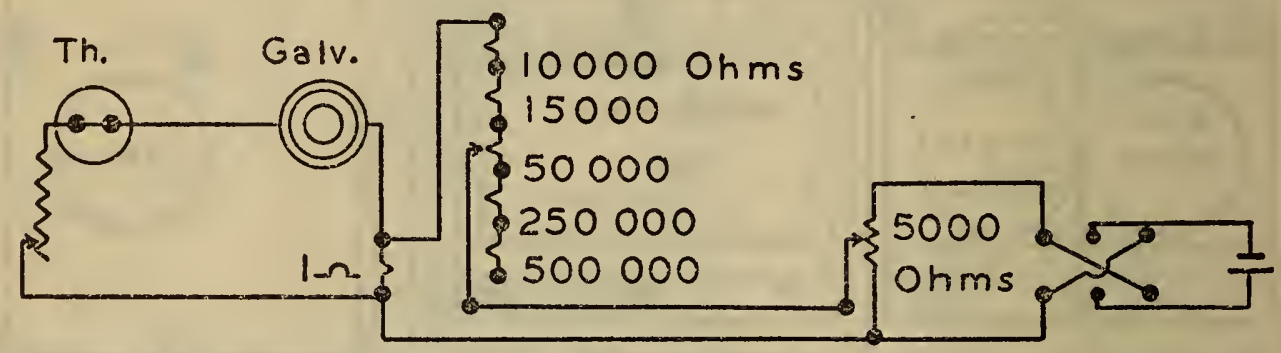

FrgURE 3.-Electrical connections to keep the galvanometer needle adjusted to the zero reading

2. The thermocouple receivers were covered with a $1 \mathrm{~cm}$ cell of water and also a purple glass filter, G986A, which reduces the heating of the water by sunlight.

For artificial sources emitting ultra-violet radiation of wave lengths less than $270 \mathrm{~m} \mu$, where the purple glass begins to absorb considerably (8), also owing to the fact that this glass decreases in transmission on exposure to ultra-violet radiation, it seems preferable to use only the cell of water, or a plate of quartz 1 to $2 \mathrm{~cm}$ in thickness to absorb the infra-red rays. Since fused quartz may absorb considerable ultraviolet of wave lengths less than $250 \mathrm{~m} \mu$ (8) it is desirable to use windows of crystalline quartz. If the outer walls of the cell are of glass, which is dissolved by distilled water, thus decreasing the ultraviolet transmission, (9) it is desirable to renew the water daily.

\section{(a) THE EXCLUSION FILTER}

This combination is depicted in Figure $2, A$. It consists of a bariumflint glass that shuts out the ultra-violet, and a plate of crystalline quartz or Corex-G980A glass that freely transmits the ultra-violet to be evaluated. Both should have the same spectral transmission throughout the rest of the spectrum of wave lengths longer than about $400 \mathrm{~m} \mu$. 
Since it was desired to evaluate the ultra-violet radiation of wave lengths less than and including $313 \mathrm{~m} \mu$ the barium-flint glass filter was selected of such a thickness (about $3.1 \mathrm{~mm}$ ) that the transmission at $313 \mathrm{~m} \mu$ is small (about 0.5 per cent), so as to provide an easily determined end point of transparency. Such a filter transmits 49 to 50 per cent at $334 \mathrm{~m} \mu, 84$ to 85 per cent at $365 \mathrm{~m} \mu$, and 89 to 90 per cent at $405 \mathrm{~m} \mu$. This kind of glass has the sharpest cut-off yet found. It does not decrease in transparency on exposure to ultraviolet radiation (exposure test of 30 hours at $15 \mathrm{~cm}$ from a 110 -volt quartz mercury arc), hence, the transmission does not require redetermination.

Throughout the visible and near infra-red spectrum the bariumflint and the Corex-G980A glasses, used in the present work, had closely (within 0.3 per cent) the same transmission, and hence, on exposing this combination to sunlight there was but little unbalancing of the thermopile caused by the difference in transparency of these two glasses for radiation of wave lengths longer than $400 \mathrm{~m} \mu$.

However, Corex G980A begins to absorb in the region of $250 \mathrm{~m} \mu$ and, since it is affected by short wave length ultra-violet rays (8), a plate of crystal quartz $1.5 \mathrm{~mm}$ in thickness was used in preference to the Corex filter in making the herein recorded measurements on artificial sources of ultra-violet radiation.

It is relevant to add that it is of great importance to keep these filters clean and free from dust. Hence, they should be mounted in holders in such a manner that they can be easily removed for cleaning, as indicated in Figure 2.

The general arrangement for mounting the thermopile and holding the filters when making measurements on the sun is shown in Figure 1 of the previous publication (1).

\section{(b) EXCLUSION FILTER CORRECTIONS}

Since the exclusion filter of barium flint glass and its long wave length radiation-balancing filter of quartz, or of Corex G980A glass, do not have exactly the same transmission throughout the spectral range from about 400 to $1,400 \mathrm{~m} \mu$ (when using the water cell, or to $3,000 \mathrm{~m} \mu$ when using a thick quartz plate instead of a cell of water) the amount of unbalancing (the thermopile deflection produced) by the radiation in this spectral range is determined experimentally by temporarily covering the thermopile (fig. 1, A) with a filter of Noviol-A glass, that has a transmission of 1 per cent or less at $405 \mathrm{~m} \mu, 55$ to 60 per cent at $436 \mathrm{~m} \mu$ (12), and completely absorbs the ultra-violet of wave lengths less than $400 \mathrm{~m} \mu$. (See fig. 2, B.) The exclusion filters (fig. 2, $A$ ) are inserted under this filter and the galvanometer deflections noted. This deflection, after correction for absorption by the Noviol filter, is deducted from the observed galvanometer deflection produced by inserting only the barium flint and quartz combination of exclusion filter. (See Table 3.) Since this correction is a secondary matter and is practically negligible when making the measurements through the purple filter G986A, an exact determination of the transmission of the Noviol filter is not necessary. For example, the transmission of a Noviol-C filter for sunlight of all wave lengths to $1,400 \mathrm{~m} \mu$ was 69 per cent; whereas by using only radiation of wave lengths 365 to $1,400 \mathrm{~m} \mu$ (by covering the thermocouple receiver with a plate of Cruxite glass) 
the transmission was increased to 71 per cent, a difference of only 2 per cent to be applied to a correction that is less than 10 per cent of the total value measured.

For determining the transmission of the Corning Noviol-A filter (82 per cent) the diaphragm (fig. 2, $C$ ) is inserted in front of the thermocouple receiver which is covered with a plate of Cruxite glass, a shutter is provided, and the galvanometer deflection is noted with and without the Noviol glass inserted in the path of the incident radiation.

(c) COMPARISON OF A CELL OF WATER AND A THICK PLATE OF QUARTZ FOR EXCLUDING THE INFRA-RED

Although the thermocouple is well balanced radiometrically, it is desirable to exclude from it as much of the infra-red and the visible radiation as possible. Furthermore, since the barium flint glass and the balancing filter of quartz or Corex G980A glass do not have the same transmission beyond $2 \mu$ in the infra-red it may be simpler for interpreting the data, to exclude the infra-red by means of a 1-cm cell of water, which is opaque to wave lengths longer than $1.4 \mu$.

However, since the water cell can not be exposed to the sun continuously without overheating and the consequent formation of bubbles on the windows, conditions may arise where it is desirable to replace the water cell by a thick plate of crystal quartz, which, in thicknesses of 1 to $2 \mathrm{~cm}$, is practically opaque to radiation of wave lengths longer than $4 \mu$.

The accuracy in measuring ultra-violet solar radiation of wave lengths less than $313 \mathrm{~m} \mu$, when the water cell was replaced (alternately) by a plate of crystal quartz $1 \mathrm{~cm}$ in thickness was tested by direct measurement (on July 8, 1931) following the "experimental procedure" described in the second following caption.

The day was extremely hot and sultry and the measurements were terminated by cirrus clouds, which decreased the accuracy of the work. Furthermore, the greater transparency of the plate of quartz to infra-red rays produced a greater heating of the thermopile container, and consequently a greater unsteadiness of the galvanometer reading. Nevertheless, in spite of these hindrances, as shown in the central part of Figure 5 (for July 8, 1931), the data obtained (a) with the water cell and $(b)$ with the $1 \mathrm{~cm}$ plate of quartz (in both cases with and without the additional purple filter of G986A glass) are in good agreement. This shows that, in spite of theoretical objections, a thick plate of quartz appears to be a good substitute for the water cell in apparatus that is to be exposed continuously to solar radiation.

It is relevant to add that one reason for the successful operation of the device is probably owing to the fact only a very small amount of the total incident solar radiation is of wave lengths longer than $2 \mu$, whereas the great deviations in transparency of the exclusion filters occur at wave lengths longer than $2 \mu$. Another item of interest is that the correction for infra-red radiation (as determined with the Noviol filter) is practically the same when using the thick quartz plate as for the water cell. This is owing to the fact that the quartz plate transmits appreciably more of the ultra-violet than the water cell. This leaves the relative proportions of solar radiation transmitted and excluded by the barium flint glass filter about the same for the quartz plate as when the water cell is used. 


\section{CALIBRATION OF THE THERMOCOUPLE}

To calibrate the balanced thermocouple radiometer the cell of water is removed from the holder, the diaphragm (fig. 2, C) is inserted and the galvanometer deflection (plus or minus) is noted when one thermocouple receiver is exposed to a standard of radiation (3). The: diaphragm is then reversed and the other receiver is exposed to the radiation standard.

The radiant flux of the standard lamp (in microwatts per $\mathrm{cm}^{2}$ ): divided by the average of the two deflections gives the calibration in: microwatts per $\mathrm{cm}^{2}$ for $1 \mathrm{~cm}$ deflection of the galvanometer.

As described in the previous publication (1) the evaluation of the measurements in absolute value, when using the single thermocouple receiver, Method I was obtained from a knowledge of the total solar radiation intensity, $Q$, amounting to some $90,000 \mu \mathrm{w}$ (microwatts) per $\mathrm{cm}^{2}$, which data were supplied by the United States Weather Bureau.

In the herein described balanced thermocouple method of measuring ultra-violet solar radiation (Method II) the calibration is obtained by exposure to a standard of radiation of $300 \mu \mathrm{w} / \mathrm{cm}^{2}$. This is a three hundredfold difference in intensity involved in the energy evaluation in absolute measure. Nevertheless, as will be seen on a subsequent page, the concordance of the data seems to indicate that the methods are reliable.

\section{EXPERIMENTAL PROCEDURE}

The method of operation of the balanced thermocouple device is extremely simple. No shutter is used. The balanced thermopile (with $(a)$ the water cell or $(b)$ with the water cell and the purple glass filter, G986A) is exposed to the source of radiation and the zero position of the galvanometer reading is noted.

If the zero position is markedly displaced from that used in calibrating the thermocouple against the standard of radiation, it is adjusted to the latter zero reading by means of the current balancing device illustrated in Figure 3, which procedure is essentially the same as balancing a bolometer. By changing the circuit slightly the device might be used as a null instrument, reading the current from the dry battery through a milliammeter or microammeter, instead of the direct galvanometer deflection. For low intensities of ultra-violet radiation the writers prefer to use the direct galvanometer deflection.

The exclusion filter (fig. 2, $A$ ) is then inserted with the barium flint glass over, say, the left receiver and the galvanometer deflection (positive or negative) caused by the excess ultra-violet radiation passing through the quartz (or Corex G980A glass) is noted. The filter is then withdrawn and the galvanometer deflection is corrected for the zero shift, if any has occurred.

The exclusion filter is then inserted in the reverse position so that the barium flint glass covers the right-hand receiver, and the galvanometer deflection (now in the opposite direction) is again noted and corrected for zero shift if any has occurred. The average of these two deflections is a measure of the total radiation shut out by the barium flint glass filter, including a few per cent of wave lengths longer than $400 \mathrm{~m} \mu$. 
To eliminate the radiation of wave lengths longer than about 400 $\mathrm{m} \mu$ the Noviol filter is inserted and a set of measurements, similar to the preceding one, is obtained, using the barium flint glass, first over the one, then over the other receiver, as already described. This value corrected for incomplete transparency of the Noviol glass is then deducted from the first set of measurements, giving the total ultra-violet shut out. To determine the amount of radiation of wave lengths less than $313 \mathrm{~m} \mu$ it is necessary to observe the relative spectral ultra-violet energy distribution of the source.

As already noted, the balanced thermopile of bismuth-copper, illustrated in Figure 1, $F$, requires an insensitive d'Arsomal galvanometer, when making measurements of the ultra-violet in direct sunlight. By using the ironclad Thomson galvanometer on a short period, with $1,000 \mathrm{ohms}$ in series $(30,000 \mathrm{ohms}$ for making the transmission measurements of the Noviol glass) with this thermopile, it is possible to make measurements of the high intensity ultra-violet radiation in direct sunlight. Similarly by decreasing the resistance in series with the galvanometer it is possible to measure the low intensity (amounting to only a few microwatts per $\mathrm{cm}^{2}$ ) emitted from certain artificial sources.

\section{REDUCTION OF OBSERVATIONS ON ULTRA-VIOLET SOLAR RADIATION}

Under this caption data are presented on the amount of ultraviolet of wave lengths less than $313 \mathrm{~m} \mu$ in sunlight as measured by a single thermocouple receiver and two exclusion filters of barium flint glass, designated Method I, previously described (1), and by a balanced thermocouple with a single exclusion filter of barium flint glass, designated Method II mentioned in the previous paper (1) and more fully described in the present paper. The concordance of the results obtained by these two methods is impressive when we consider the widely different methods of making the measurements and evaluating the results in absolute value.

In Method I, the purple glass filter transmits about 8 per cent of the total incident solar radiation amounting to about $90,000 \mu \mathrm{W}$ (microwatts) per $\mathrm{cm}^{2}$. This 8 per cent consists of violet and ultraviolet radiation of wave lengths less than $400 \mathrm{~m} \mu$ (also some near infra-red radiation).

The total galvanometer deflection that can be conveniently used, without encumbering the work by changing the sensitivity, is 20 to $25 \mathrm{~cm}$. By inserting the filters of barium flint glass the amount of ultra-violet of wave lengths less than $365 \mathrm{~m} \mu$, which is excluded, amounts to only a few per cent (a few millimeters) of the total observed galvanometer deflection. Nevertheless, as shown in previous papers (1) and (8), comparison of this deflection with the standard of radiation gives values which are in good agreement with data calculated by using the total solar radiation data, $Q$, obtained from the United States Weather Bureau.

In Method II the total galvanometer deflection observed is from 12 to $15 \mathrm{~cm}$ (or larger by changing the galvanometer sensitivity), and, depending upon the solar altitude, the amount of ultra-violet of wave lengths less than about $365 \mathrm{~m} \mu$ (in which we are particularly interested, 
as in Method I), is 90 to 95 per cent of this value when using the purple glass filter G986A, and 60 to 70 per cent of this value when purple glass filter is not used.

\section{REDUCTION OF DATA OBTAINED BY METHOD I}

The general procedure in reducing the observations, using the single thermocouple receiver and two barium flint exclusion filters, remains the same as previously described (1). An important change is introduced by a recalculation of the reduction factors, $F$, depicted

Air Mass

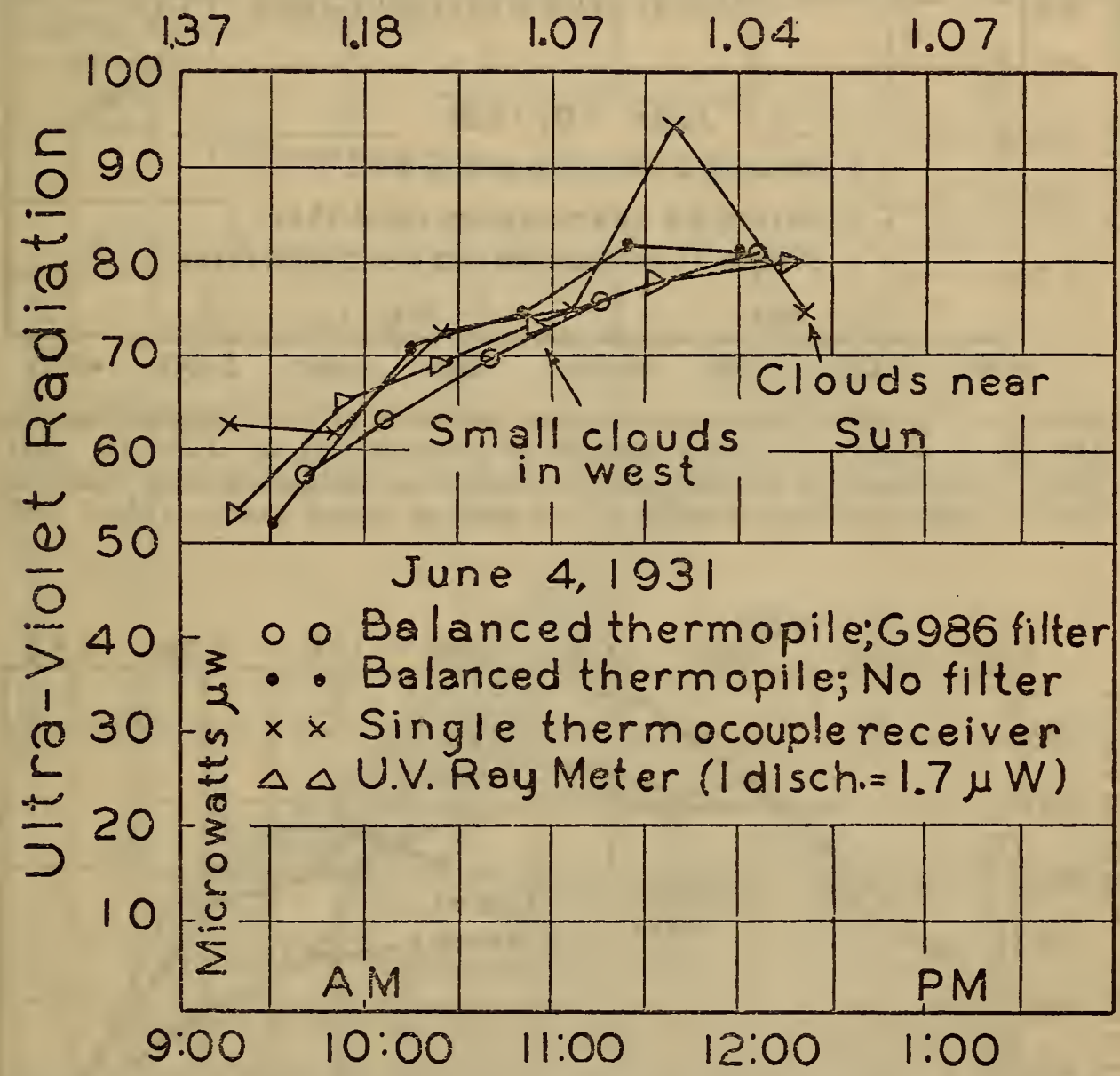

FIGURE 4.-Variation in ultra-violet solar radiation of wave lengths less than $313 \mathrm{m \mu}$ as observed by four methods of measurement

in Figure 5 of the previous publication (1). This change is introduced by using an observed solar spectral energy curve that represents more closely the observed per cent transmissions of the barium flint glass filters $\left(a / I_{0}\right.$ and $\left.a+b / a\right)$ than the calculated values depicted in Figures 3 and 4 of the previous publication (1). The new factors, $F$, are on an average, about 20 to 25 per cent higher than previously used.

New factors are introduced for eliminating the absorption at 290 to $313 \mathrm{~m} \mu$ by the water cell and the purple glass filter G986A, amounting to 15 and 21 per cent, respectively.

Aś shown in Figures 4, 5, and 6, the average amount of ultra-violet solar radiation of wave lengths less than $313 \mathrm{~m} \mu$, for midlatitude sea 


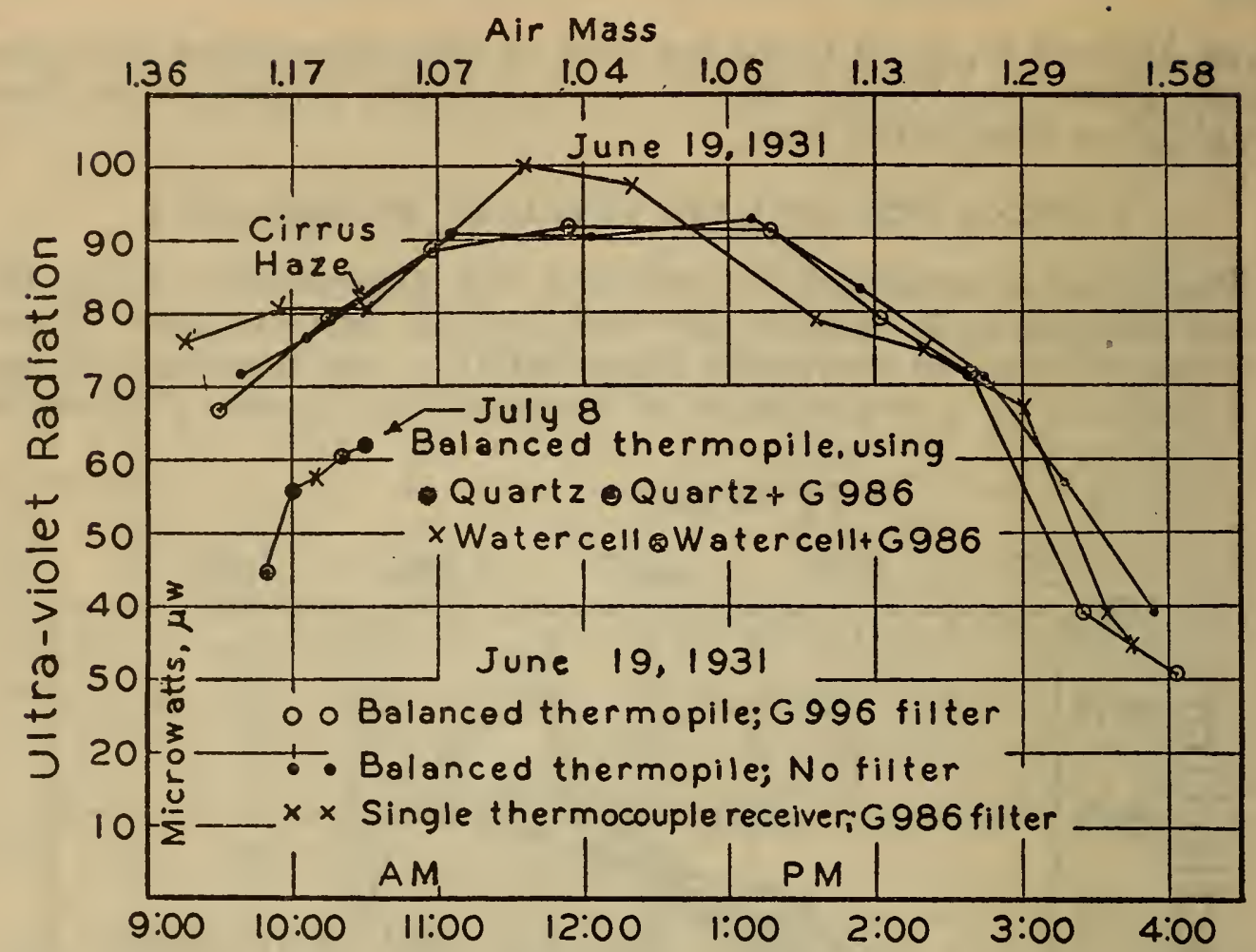

FIGURE 5.-Variation in ultra-violet solar radiation of wave lengths less than $313 \mathrm{m \mu}$ as observed by three methods of measurement, on June 19, 1931. Also a comparison of the accuracy in measuring ultra-violet solar radiation when the water cell is replaced by a $1 \mathrm{~cm}$ plate of crystal quartz, July 8, 1931

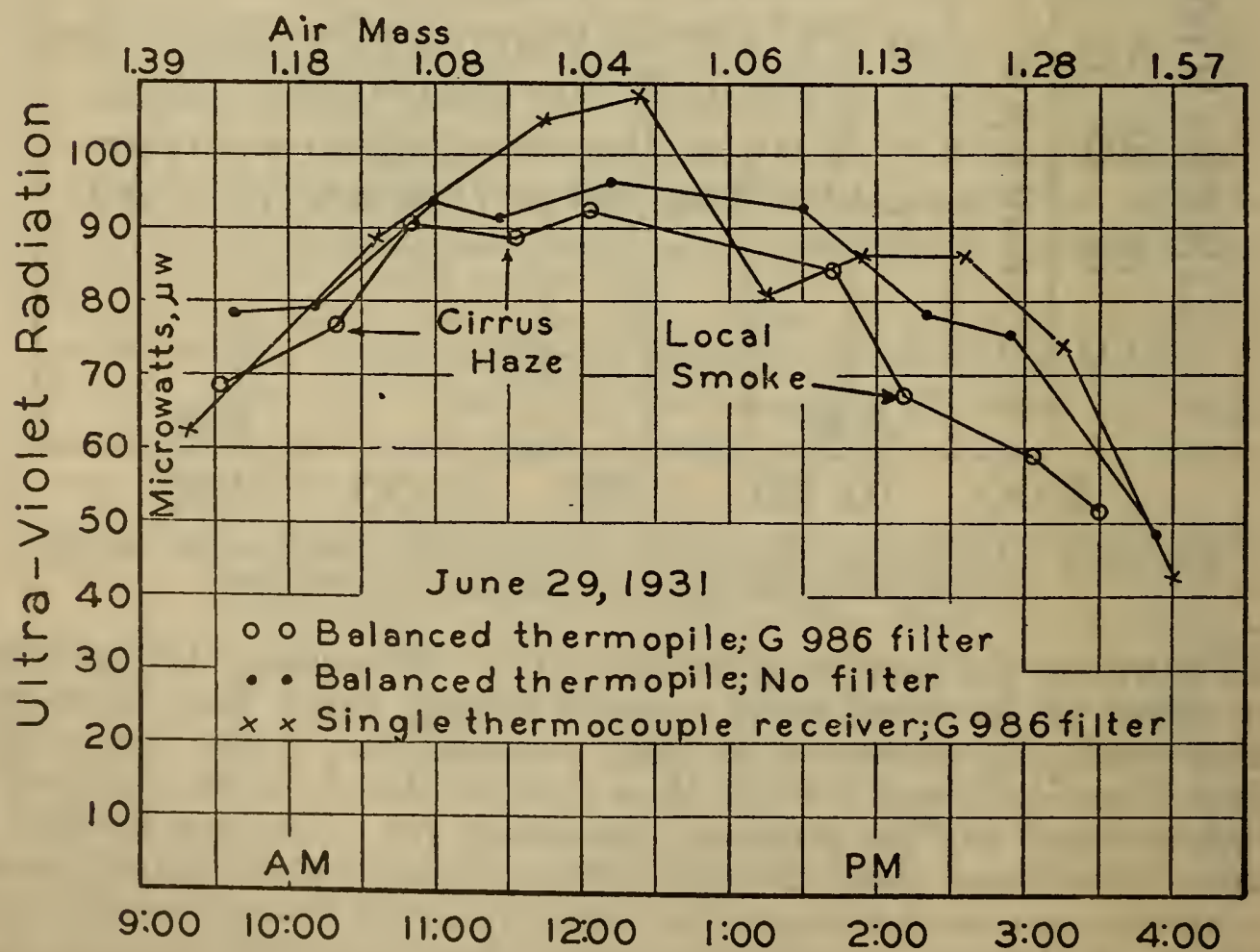

FIGURE 6.-Variation in ultra-violet solar radiation of wave lengths less than $313 \mathrm{m \mu}$ as observed by three methods of measurement 
level stations, during the clearest weather, during midday in midsummer, averages about $90 \mu \mathrm{w} / \mathrm{cm}^{2}$ instead of $55 \mu \mathrm{w} / \mathrm{cm}^{2}$ as previously published (1).

In the absence of an exact knowledge of the spectral energy curve of the sun, at the time of making the observations, it remains uncertain as to which values, obtained by Method I, are the more nearly correct. However, fortified with the data obtained by Method II, described in the next section, it appears that on the basis of the present work, the previously published data, using Method I should be increased by perhaps 50 per cent, instead of 10 to 20 per cent, previously estimated (1). Until a better knowledge is obtained of the solar spectral energy curve some uncertainty must remain regarding the factor $F$, used in evaluating the ultra-violet radiation of wave lengths less than $313 \mathrm{~m} \mu$ in sunlight.

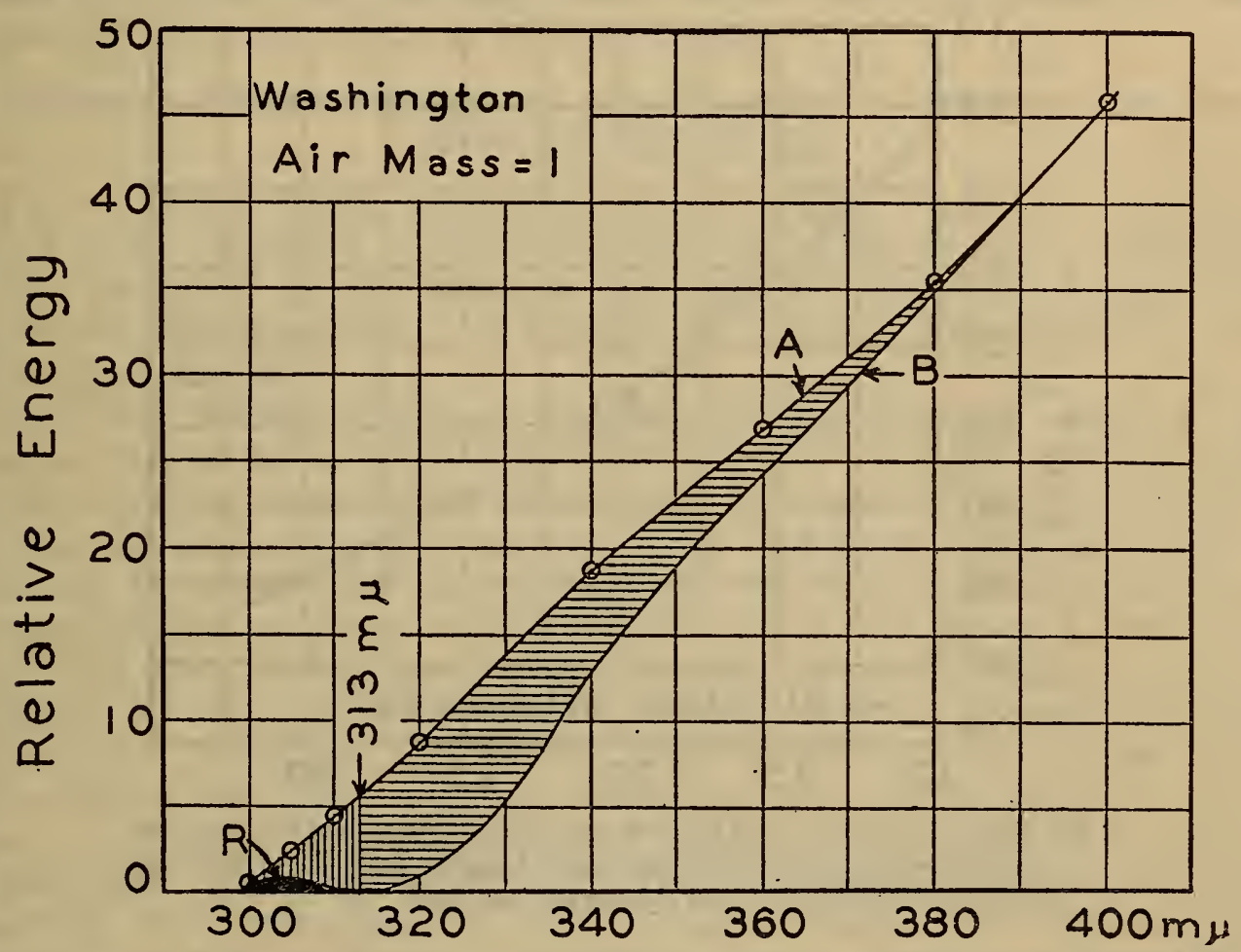

FIGURE 7.-Graphical method used in reducing the data

\section{REDUCTION OF DATA OBTAINED BY METHOD II}

The reduction factor, $F$, for obtaining the amount of ultra-violet radiation of wave lengths less than $313 \mathrm{~m} \mu$, when using the balanced thermocouple and single barium flint glass exclusion filter, is obtained as illustrated in Figure 7, in which $A$ is the observed solar spectral energy curve (1) and $B$ is the spectral transmittance curve of the barium-flint glass filter, on the assumption that both the flint glass and the nonabsorbing screen (quartz or Corex G980A) have the same transparency to wave lengths longer than $400 \mathrm{~m} \mu$. The procedure given in the previous paper (1) is followed in obtaining the factor, $F$, for different air masses. These factors are given in Figure 8. They indicate that the amount of ultra-violet of wave lengths less than, and including $313 \mathrm{~m} \mu$ (which wave length is important in integrating the spectrum of the quartz mercury arc) ranges from about 6 per cent 
of the total shaded area in Figure 7, for air mass, $m=3$, to 12 per cent for air mass, $m=1$.

The reduction of the data is relatively simple. A sample illustration of the method is given in Table 1 in which column $d$ gives the average observed deflection on insertion of the barium-flint glass exclusion filter. (Fig. 2, A.)

Column $e$ gives the galvanometer deflection indicating the amount of radiation of wave lengths longer than $400 \mathrm{~m} \mu$, obtained by covering the thermocouple with the Noviol filter, and corrected by dividing the observed deflection by the transmission (71 per cent) of the filter. Column $f$ (which is column $d$ minus column $e$ ) gives the observed ultra-violet excluded by the barium flint glass filter.

Column $g$ gives the factor, $F$, to reduce the amount of the total radiation measured (column $f$ ) to that of wave lengths less than 313 $\mathrm{m} \mu$.

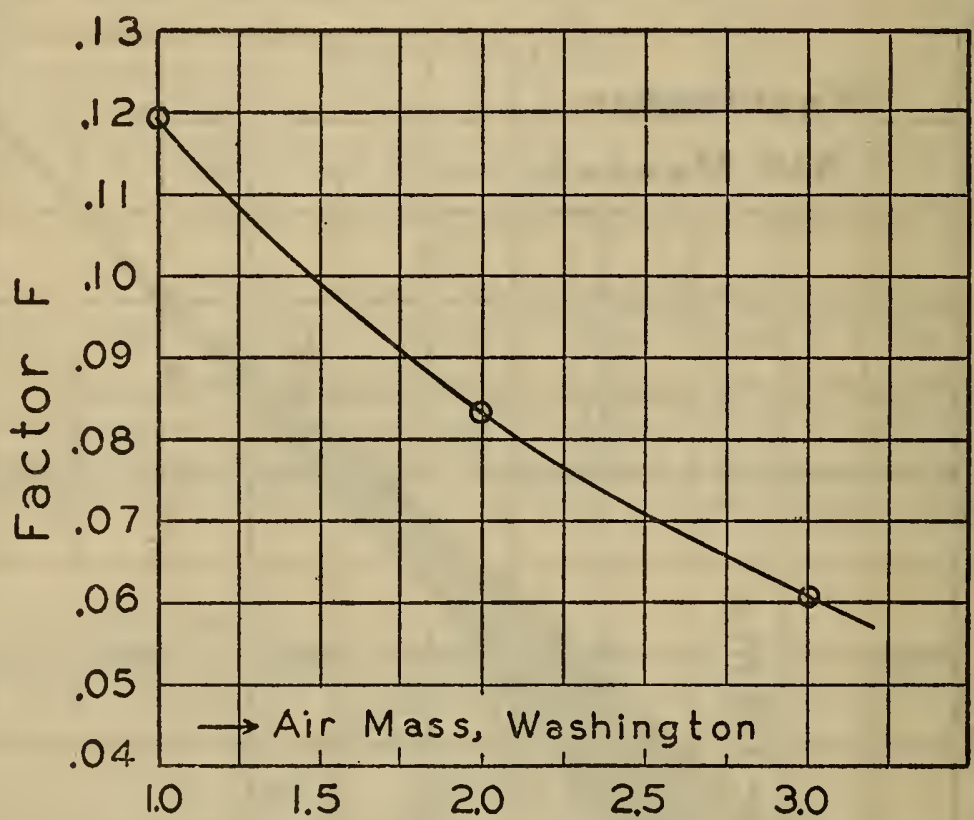

FIgURE 8.-Reduction factors used in determining the amount of ultra-violet radiation of wave lengths less than $313 \mathrm{m \mu}$ using the balanced thermocouple method.

Column $h$ is the experimentally observed factor that must be applied to column $f$, because of absorption of radiation of wave lengths less than $313 \mathrm{~m} \mu$ by the water cell, the Corex G980A glass, and the fluorite window which covers the thermocouple receivers.

Column $i$ is the radiation sensitivity of the thermopile in microwatts per $\mathrm{cm}^{2}$ for $1 \mathrm{~cm}$ deflection, observed by exposure to the standard of radiation.

Column $j$, which is the product of columns $f, g, h$, and $i$, is the total amount of ultra-violet solar radiation of wave lengths less than 313 $\mathrm{m} \mu$ available at 10.50 to 10.59 a. m., June 29,1931 .

On this day, sky conditions were as follows:

Clear at 9 a. m.; cirrus clouds east of the-sun at 10.30 a. m.; sky mottled near the sun at 11.30 a. m.; sky relatively clear during the afternoon, except a local fire of short duration with smoke rising southwest of the sun, which did not appear to be in the line of sight, but which may have caused the depression in the curve at $2.15 \mathrm{p} . \mathrm{m}$. (See fig. 6.) 
TABLE 1.-Reduction of data observed on June 29, 1931

\begin{tabular}{|c|c|c|c|c|c|c|c|c|c|}
\hline Time & Filter & $\begin{array}{l}\text { Air } \\
\text { mass }\end{array}$ & $\begin{array}{c}\text { Ob- } \\
\text { served } \\
\text { galv.de- } \\
\text { flection }\end{array}$ & $\begin{array}{l}\text { Infra- } \\
\text { red cor- } \\
\text { rec- } \\
\text { tion }\end{array}$ & $\begin{array}{l}\text { Differ- } \\
\text { ence }\end{array}$ & $\underset{F}{\text { Factor }}$ & $\begin{array}{l}\text { Filter } \\
\text { factor }\end{array}$ & $\begin{array}{l}\text { Ther- } \\
\text { mopile } \\
\text { sensi- } \\
\text { tivity }\end{array}$ & $\begin{array}{l}\mu \mathrm{W} / \mathrm{cm}^{2} \\
\text { below } \\
313 \mathrm{~m} \mu\end{array}$ \\
\hline a & b & c & d & e & f & $\mathrm{g}$ & h & i & $\mathbf{j}$ \\
\hline $\begin{array}{l}\text { a. } m . \\
10.50 \\
10.59\end{array}$ & $\begin{array}{l}\text { Water cell and G986 } \\
\text { Water cell }\end{array}$ & $\begin{array}{l}\text { 1. } 09 \\
1.08\end{array}$ & $\begin{array}{c}c m . \\
5.51 \\
11.15\end{array}$ & $\begin{array}{l}c m . \\
0.37 \\
4.24\end{array}$ & $\begin{array}{l}c m . \\
5.14 \\
6.91\end{array}$ & $\begin{array}{l}0.115 \\
.116\end{array}$ & $\begin{array}{r}0.172 \\
.132\end{array}$ & $\begin{array}{r}\mu \mathrm{w} / \mathrm{cm} m^{2} \\
88.5 \\
88.5\end{array}$ & $\begin{array}{l}90.0 \\
93.6\end{array}$ \\
\hline
\end{tabular}

Some of the other observations of ultra-violet solar radiation, made on the same day using Method I and the two modifications of Method II (practically three methods in all) are illustrated in Figures 4 and 5 , showing the close agreement in the results obtained by these markedly different methods of observation.

\section{SUMMARY COMPARISON OF EXPERIMENTAL PROCEDURE AND RESULTS OBTAINED}

The relatively close agreement in the measurements of the ultraviolet solar radiation, during the clearest summer days, extending over a period of several months (and partly illustrated in figs. 4, 5, and 6 ) is significant and can hardly be considered accidental for the following reasons:

(a) Two widely different radiometric methods of making the measurements were used-Method I with a single thermocouple receiver and two exclusion filters, and Method II with a balanced thermopile and one exclusion filter; $(b)$ widely different methods of reducing the data were employed, using factors based upon an average energy curve of the whole solar spectrum in Method I, and upon only the ultra-violet portion of the solar spectral energy curve in Method II; and $(c)$ two widely different methods of evaluating the ultra-violet radiation in absolute units were used-in Method I by using the total solar radiation intensity, Q, and in Method II by direct calibration of the thermopile against a standard of radiation. While these two methods of calibration are interchangeable, it seems desirable to standardize the galvanometer reading by exposing the thermopile to a standard source that emits radiation comparable in intensity with the total (ultra-violet) measured.

From these data it appears that the average amount of ultra-violet solar radiation of wave lengths less than, and including $313 \mathrm{~m} \mu$, for mid-latitude sea-level stations, during the clearest weather, during midday, in midsummer, amounts to about $90 \mu \mathrm{w} / \mathrm{cm}^{2}$, decreasing to about $20 \mu \mathrm{w} / \mathrm{cm}^{2}$ on the clearest days in December.

\section{INTEGRATION OF ULTRA-VIOLET RADIATION BY SPECTRORADIOMETRIC AND BY FILTER METHODS}

As indicated in the introductory part of this paper, the élite method of measuring the intensity of ultra-violet radiation is by means of a spectroradiometer, with the source at a known distance from the entrance slit. However, the method is beset with difficulties, especially when the problem is presented to measure the radiation from an extended source. Hence, it is desirable to obtain some filter 
method for quickly and accurately measuring the integrated ultraviolet radiation from sources used for therapeutic purposes.

Under this caption comparative data are given of the ultra-violet radiation emitted by a tungsten mercury arc lamp, in a quartz bulb, as observed (1) with a spectroradiometer, and (2) with a balanced thermopile and a barium flint glass exclusion filter already described.

\section{THE SPECTRORADIOMETRIC METHOD}

The spectroradiometer consisted of two uncemented quartz fluorite achromatic lenses $33 \mathrm{~mm}$ in diameter and $30 \mathrm{~cm}$ focal length, and a prism of quartz $6 \mathrm{~cm}$ in height. The fluorite used in the lenses was of the yellow variety, and, while it appeared quite colorless in the thickness used, it had a small absorption in the blue and violet, followed by a relatively high transmission in the ultra-violet.

To facilitate setting on a spectral line, the slit was given a thin coat of turpentine upon which was dusted a thin deposit of anthracene, which was then rubbed smooth. Starting with the slit closed, this method of applying the fluorescent material produces a sharp knifeedge, which, on opening the slit permits an accurate isolation of closely adjoining emission lines.

The size of the entrance slit was 5.0 by $0.50 \mathrm{~mm}$, and the exit slit was 5.3 by $0.60 \mathrm{~mm}$. The radiation sensitivity of the thermopile back of the exit slit was obtained by exposing the exit slit to the standard of radiation. Since the area of the exit slit was 1.283 times larger than the entrance slit, and since, for small variations in slit opening, the galvanometer deflection is proportional to the size of the thermopile receiver that is exposed to radiation, this slit factor, $f$, must be applied in Table 2 .

The factor, $h$, for reducing the data in Table 2 , to a distance of $1 \mathrm{~m}$ is 0.01613 .

The radiation sensitivity of the thermopile, corrected by the transmission (91.6 per cent) of the fluorite window, was $1 \mathrm{~cm}$ deflection $=$ $12.05 \mu \mathrm{w} / \mathrm{cm}^{2}$. At each spectrometer setting the galvanometer deflection is multiplied by this factor, $e$, in Table 2 , to reduce the data to absolute units.

The galvanometer deflections must be corrected also for the loss in transmission through the spectroradiometer. (Column $c$ in Table 2.) The transmission of the quartz-fluorite spectroradiometer (2) was determined by isolating spectral lines with a quartz monochromator and measuring the intensities by means of two thermopiles, one placed at the entrance slit and the other at the exit slit of the spectroradiometer. As a check on the accuracy when using two thermopiles, the vacuum thermopile (usually employed at the exit slit) was used to measure the intensity of the $365 \mathrm{~m} \mu$ line, at both the entrance and the exit slit. The same transmissions, within 0.5 per cent, was observed by the two methods.

In these measurements, at each wave length the apparatus was adjusted so that the lenses and prism were uniformly irradiated with monochromatic light. To trace the ultra-violet beam of radiation through the spectrometer, it was made luminous by inserting in the path a piece of white cardboard covered with a thin film of turpentine upon which anthracene was dusted and rubbed smooth.

In order to correct for scattered radiation when making measurements at wave lengths longer than $313 \mathrm{~m} \mu$ a red or amber glass shutter 
was used. For wave lengths 313 to $280 \mathrm{~m} \mu$ the shutter was of clear window glass, and for wave lengths less than $280 \mathrm{~m} \mu$. Helioglass was used.

The source was a new type of tungsten mercury arc (2) in which the ultra-violet radiation from a $V$-shaped helical filament of tungsten wire is supplemented by the radiation from a mercury vapor arc across two tungsten electrodes at the top of the $\mathrm{V}$-shaped filament.

The measurements were made with a vacuum thermopile described in previous papers. The ultra-violet spectral transmission of the fluorite window is given in column $d$ of Table 2.

In order to obtain sufficient intensity, and in order to uniformly irradiate the whole lens, the lamp was operated at a distance of 12.7 $\mathrm{cm}$ from the entrance slit. This is important, since, in measuring the transmission of the spectroradiometer, the whole lens was irradiated. The radiation from the whole lamp including the bulb is 4.4 per cent larger. This is factor $g$ in Table 2.

The observed intensities (the galvanometer deflections) of the strong emission lines and of the continuous spectrum, are given in column $b$ of Table 2 ; also the absolute values of these intensities, deduced as just described.

The sum of the intensities of all the radiation shorter than and including the emission lines at $313 \mathrm{~m} \mu$, amounts to $23.9 \mu \mathrm{w} / \mathrm{cm}^{2}$, which is somewhat lower than the value obtained by the filter method. This is to be expected in view of the fact that no spectroradiometric measurements were made on the weak radiation between 365 and $436 \mathrm{~m} \mu$, and at the wave lengths shorter than $230 \mathrm{~m} \mu$.

TABLE 2.-Ultra-violet spectral intensities, in microwatts $/ \mathrm{cm}^{2}$ at $1 \mathrm{~m}$, from a tungsten mercury arc in a quartz bulb

[The correction factors, $e$ for the radiation sensitivity of the thermopile, $f$ for difference in areas of the slits, $g$ for size of lamp image on prism, and $h$ for distance of lamp from the entrance slit, are described in the text]

\begin{tabular}{|c|c|c|c|c|}
\hline $\begin{array}{l}\text { Wave } \\
\text { length }\end{array}$ & $\begin{array}{l}\text { Observed } \\
\text { galva- } \\
\text { nometer } \\
\text { deflection }\end{array}$ & $\begin{array}{l}\text { Spectrom- } \\
\text { eter } \\
\text { trans- } \\
\text { mission }\end{array}$ & $\begin{array}{l}\text { Transmis- } \\
\text { sion, fluo- } \\
\text { rite window } \\
\text { on thermo- } \\
\text { pile }\end{array}$ & $\begin{array}{l}\text { Absolute intensity at } \\
1 \mathrm{~m} ; \text { Cols. } \\
\frac{b \times e \times f \times g \times h}{c \times d}\end{array}$ \\
\hline a & b & c & d & $\mathbf{i}$ \\
\hline $\begin{array}{r}m_{\mu} \\
365 \\
365-334 \\
334 \\
334-313\end{array}$ & $\begin{array}{r}c m \\
12.75 \\
1.04 \\
.98 \\
.49\end{array}$ & $\begin{array}{r}0.398 \\
.390 \\
.377 \\
.360\end{array}$ & $\begin{array}{r}0.900 \\
.895 \\
.890 \\
.885\end{array}$ & $\begin{array}{l}\mu w / \mathrm{cm}^{2} \\
9.27 \\
.77 \\
.76 \\
.40\end{array}$ \\
\hline 313 & 10. 39 & .344 & .880 & 8.94 \\
\hline $\begin{array}{l}302 \\
297 \\
289 \\
280 \\
275\end{array}$ & $\begin{array}{l}2.98 \\
2.33 \\
.56 \\
.95 \\
.37\end{array}$ & $\begin{array}{l}.322 \\
.310 \\
.292 \\
.261 \\
.245\end{array}$ & $\begin{array}{l}.875 \\
.871 \\
.869 \\
.861 \\
.859\end{array}$ & $\begin{array}{r}2.76 \\
2.25 \\
.57 \\
1.10 \\
.46\end{array}$ \\
\hline $\begin{array}{l}270 \\
265 \\
258 \\
254 \\
248\end{array}$ & $\begin{array}{r}.38 \\
1.98 \\
.25 \\
1.13 \\
.59\end{array}$ & $\begin{array}{l}.231 \\
.218 \\
.201 \\
.194 \\
.180\end{array}$ & $\begin{array}{l}.854 \\
.850 \\
.843 \\
.840 \\
.835\end{array}$ & $\begin{array}{l}.50 \\
2.78 \\
.39 \\
1.80 \\
1.02\end{array}$ \\
\hline $\begin{array}{l}241 \\
238 \\
234 \\
230\end{array}$ & $\begin{array}{l}.25 \\
.25 \\
.09 \\
.06\end{array}$ & $\begin{array}{l}.162 \\
.155 \\
.145 \\
.135\end{array}$ & $\begin{array}{l}.830 \\
.825 \\
.820 \\
.815\end{array}$ & $\begin{array}{l}.48 \\
.51 \\
.19 \\
.14\end{array}$ \\
\hline \multicolumn{4}{|c|}{ Total shorter than and including $313 \mathrm{~m} \mu \ldots$} & $23.89 \mu \mathrm{w} / \mathrm{cm}^{2}$ \\
\hline
\end{tabular}




\section{THE BALANCED THERMOPILE AND EXCLUSION FILTER METHOD}

The same procedure was followed in measuring the undispersed ultra-violet radiation from the tungsten mercury arc as was used in measuring the ultra-violet radiation from the sun, except that the balancing filter (fig. 2, A) was of quartz instead of Corex-A glass, which appreciably absorbs the wave lengths less than about $260 \mathrm{~m} \mu$.

The data are assembled in Table 3 in which column $a$ gives the observed galvanometer deflection. Column $c$ is column $a$ after correction for the amount of infra-red present (column $b$ ) determined by means of the Noviol filter as already described. Column $e$ is the radiation sensitivity of the galvanometer in microwatts per $\mathrm{cm}^{2}$, obtained by exposure to a standard of radiation, and corrected for transmission (91.6 per cent) of the fluorite window.

TABLE 3.-Integrated ultra-violet radiation of wave lengths less than, and including $313 \mathrm{m \mu}$, at $1 \mathrm{~m}$ from a tungsten mercury arc in a quartz bulb, as determined by $a$ balanced thermopile and exclusion filter radiometer

\begin{tabular}{|c|c|c|c|c|c|}
\hline $\begin{array}{c}\text { Observed } \\
\text { galva- } \\
\text { nometer } \\
\text { deflection }\end{array}$ & $\begin{array}{c}\text { Infra-red } \\
\text { correction }\end{array}$ & $\begin{array}{c}\text { Difierence; } \\
a-b\end{array}$ & $\begin{array}{c}\text { Factor } F, \\
\text { Table 4 }\end{array}$ & $\begin{array}{c}\text { Thermo- } \\
\text { pile sensi- } \\
\text { tivity, } \\
1 \mathrm{~cm}= \\
\mu \mathrm{w} / \mathrm{cm}^{2}\end{array}$ & $\begin{array}{c}\text { Total ul- } \\
\text { tra-violet } \\
\text { radiation, } \\
\text { in } \mu w / c m^{2} \\
\text { Cols. } \\
c \times d \times e\end{array}$ \\
\hline $\mathrm{a}$ & $\mathrm{b}$ & $\mathrm{c}$ & $\mathrm{d}$ & $\mathrm{e}$ & $\mathrm{f}$ \\
\hline $\begin{array}{c}c m \\
2.70\end{array}$ & $\begin{array}{c}\mathrm{cm} \\
0.73\end{array}$ & $\begin{array}{c}\mathrm{cm} \\
1.97\end{array}$ & 1.44 & 9.89 & 28.0 \\
\hline
\end{tabular}

An important factor, $F$, is the amount of ultra-violet of wave lengths less than, and including $313 \mathrm{~m} \mu$, relative to the total shutout by the barium flint glass exclusion filter.

The procedure followed in obtaining the factor, $F$, is given in Table 4 in which column $b$ is the spectral energy distribution of the radiation emitted by the lamp (taken from the last column of Table 2). These values need not be determined in absolute units.

Assuming equality of transmission of the barium fint glass and the quartz filters for wave lengths longer than $400 \mathrm{~m} \mu$ (for which a correction for inequality of transmission is made by means of the Noviol filter) column $c$ gives the difference in transmission of these two filters throughout the ultra-violet.

The observed spectral transmission of the water cell (using freshly distilled water) is given in column $d$. The balanced thermopile receivers were covered with a plate of fluorite which had the transmissions given in column $e$. The products of these factors, representing the radiation shut out by the barium flint glass filter are given in column $f$ of Table 4 . The sum of the intensities (galvanometer deflections) of all the wave lengths represents the observed amount of ultra-violet radiation excluded by the barium flint glass filter. 
TABLE 4.-Determination of the factor, $F$, for reducing the observed spectral intensity to radiation of wave lengths $313 \mathrm{m \mu}$ and less, for a tungsten mercury arc lamp

[The value of the factor $F$ is $23.89 \div 16.56=1.44$ ]

\begin{tabular}{|c|c|c|c|c|c|}
\hline $\begin{array}{l}\text { Wave } \\
\text { length }\end{array}$ & $\begin{array}{l}\text { Relative } \\
\text { intensity }\end{array}$ & $\begin{array}{c}\text { Trans- } \\
\text { mission } \\
\text { quartz } \\
\text { minus } \\
\text { barium } \\
\text { flint }\end{array}$ & $\begin{array}{c}\text { Trans- } \\
\text { mission } \\
\text { water } \\
\text { cell }\end{array}$ & $\begin{array}{c}\text { Trans- } \\
\text { mission } \\
\text { fluorite } \\
\text { on ther- } \\
\text { mopile }\end{array}$ & $\begin{array}{l}\text { Radiation } \\
\text { excluded } \\
\text { by barium } \\
\text { flint glass; } \\
\text { cols. } b \times c \\
\times d \times e\end{array}$ \\
\hline a & b & c & d & e & f \\
\hline $\begin{array}{r}400 \\
365 \\
365-334 \\
334 \\
334-313\end{array}$ & $\begin{array}{l}9.27 \\
.77 \\
.76 \\
.40\end{array}$ & $\begin{array}{l}0.00 \\
.06 \\
.17 \\
.40 \\
.64\end{array}$ & $\begin{array}{l}0.880 \\
.875 \\
.871 \\
.868 \\
.865\end{array}$ & $\begin{array}{r}0.900 \\
.891 \\
.885 \\
.878 \\
.875\end{array}$ & $\begin{array}{l}0.000 \\
.434 \\
.102 \\
.233 \\
.192\end{array}$ \\
\hline $\begin{array}{l}313 \\
302 \\
297 \\
289 \\
280\end{array}$ & $\begin{array}{l}8.94 \\
2.76 \\
2.25 \\
.57 \\
1.10\end{array}$ & $\begin{array}{l}.895 \\
.90 \\
.90 \\
.90 \\
.90\end{array}$ & $\begin{array}{l}.862 \\
.859 \\
.856 \\
.851 \\
.849\end{array}$ & $\begin{array}{l}.873 \\
.863 \\
.860 \\
.857 \\
.848\end{array}$ & $\begin{array}{r}6.020 \\
1.842 \\
1.491 \\
.374 \\
.712\end{array}$ \\
\hline $\begin{array}{l}275 \\
270 \\
265 \\
258 \\
254\end{array}$ & $\begin{array}{r}.46 \\
.50 \\
2.78 \\
.39 \\
1.80\end{array}$ & $\begin{array}{l}.90 \\
.90 \\
.90 \\
.90 \\
.90\end{array}$ & $\begin{array}{l}.840 \\
.843 \\
.841 \\
.839 \\
.837\end{array}$ & $\begin{array}{l}.845 \\
.840 \\
.837 \\
.830 \\
.825\end{array}$ & $\begin{array}{r}.295 \\
.319 \\
1.760 \\
.243 \\
1.119\end{array}$ \\
\hline $\begin{array}{l}248 \\
241 \\
238 \\
234 \\
230\end{array}$ & $\begin{array}{l}1.02 \\
.48 \\
.51 \\
.19 \\
.14\end{array}$ & $\begin{array}{l}.90 \\
.90 \\
.90 \\
.90 \\
.90\end{array}$ & $\begin{array}{l}.835 \\
.832 \\
.830 \\
.828 \\
.827\end{array}$ & $\begin{array}{l}.819 \\
.810 \\
.805 \\
.800 \\
.795\end{array}$ & $\begin{array}{l}.626 \\
.291 \\
.307 \\
.115 \\
.085\end{array}$ \\
\hline & 123.89 & & & & ${ }^{2} 16.560$ \\
\hline
\end{tabular}

1 Total present of wave lengths $313 \mathrm{~m} \mu$ and less.

2 Total excluded by the barium flint glass.

The sum of the intensities of wave lengths shorter than and including $313 \mathrm{~m} \mu$ in column $b$ represents the total amount emitted; and column $f$ is the total amount excluded by the barium flint glass filter. The ratio of these two summations $(23.89 / 16.56)$ is the factor $F=1.44$.

In other words, owing to the absorption by the water cell and the (fluorite) thermopile window, the observed average galvanometer deflection (representing the ultra-violet radiation shut out by the barium flint glass filter) given in column $c$ of Table 3, must be multiplied by the factor 1.44 in order to obtain the radiation of wave lengths less than and including $313 \mathrm{~m} \mu$ in the tungsten mercury arc.

As given in Table 3, the undispersed ultra-violet radiant flux, of wave lengths less than and including $313 \mathrm{~m} \mu$, at a distance of $1 \mathrm{~m}$, from this tungsten mercury arc lamp, as measured with the balanced thermopile and the barium flint glass exclusion filter is $28 \mu \mathrm{w} / \mathrm{cm}^{2}$. The value obtained by summation of the spectral lines is $23.9 \mu \mathrm{w} / \mathrm{cm}^{2}-\mathrm{a}$ difference of about 14.6 per cent. Since these data were obtained to illustrate the method, and not as a final crucial test of the ultraviolet efficiency of a particular type of lamp, in which case averages of several series of observations would be taken, the agreement in the two methods of measuring the integrated ultra-violet is satisfactory.

Moreover, a small difference is to be expected in the values obtained by these two widely different methods of making the measurements, because of the difficulty in measuring weak ultra-violet radiation, 
when it is resolved into a spectrum, whereas in the undispersed state it is measured as a whole by the filter method.

Using another tungsten mercury arc lamp, the same factor, $F=1.44$, was obtained. From this it appears that the factor, $F$, for a given type of lamp can be obtained by observing a limited number of samples, using the spectroradiometric method, after which it is possible to rate the performance of these lamps, on a large scale, by means of the balanced thermopile and exclusion filter method.

In conclusion, it is relevan to recall that in order to determine the factor, $F$, for a source which emits a continuous spectrum, it is necessary to reduce the intensity measurements to a normal spectrum energy distribution (13), then correct these intensities for absorption by the spectroradiometer and thermopile window. This gives the normal spectral energy flux upon the entrance slit. Since only the relative spectral in tensities are required, it is unnecessary to calibrate the galvanometer in absolute units. The evaluation of the factor, $F$, is then made as in the case of sunlight, illustrated in Figure 7.

\section{CALIBRATION OF A PHOTO-ELECTRIC CELL IN ABSO- LUTE UNITS BY MEANS OF RADIOMETRIC FILTER METHODS}

For some years the problem has been presented to calibrate and keep a check on the accuracy of a photo-electric cell, for use as an intensity, or so-called dosage meter of ultra-violet radiation, used in heliotherapy.

With the herein described satisfactory tests of unselective radiometer-filter methods, particularly the balanced thermocouple and filter radiometer, it is believed that a way has been found for calibrating and for testing the constancy of the performance of selective (photo-electric) radiometers for use in measuring ultra-violet radiation.

The particular device studied was a Rentschler "ultra-violet ray meter" (11) consisting of a photo-electric cell connected with a counting device.

As shown in Figure 4 (the triangles $\Delta \Delta \Delta$ ) the number of discharges of the condenser through the glow relay tube, which is connected with the photo-electric cell, is proportional to the intensity of the ultra-violet radiation (from the sun and a large part of the sky) incident upon the cell. The intensity or flux density of ultra-violet radiation of wave lengths less than $334 \mathrm{~m} \mu$ (the long wave length limit of sensitivity of the particular cell used) represented by a single discharge through the glow relay tube, in midwinter (air mass, $m=1.6$ ) was 1 discharge $=2.6 \mu \mathrm{w} / \mathrm{cm}^{2}$, and in midsummer $(m=1.05$ to $m=1.3)$ it was 1 discharge $=1.7 \mu \mathrm{w} / \mathrm{cm}^{2}$. Another cell, which had been used only a few times, varied from 1 discharge $=1.9 \mu \mathrm{w} / \mathrm{cm}^{2}$ in winter to 1 discharge $=1.35 \mu \mathrm{w} / \mathrm{cm}^{2}$ in midsummer.

These data are interesting in showing that whereas the rate of discharge appears to be proportional to the intensity (see fig. 4) for small changes in air mass, yet the constant of the instrument (the value of 1 discharge in $\mu \mathrm{w} / \mathrm{cm}^{2}$ ) appears to be smaller in summer than that observed in winter. This would occur if, as is generally supposed, the summer sun is richer in short wave length ultra-violet than winter sunlight. The cell intercepts also a large part of the sky, which may affect the constant of the instrument. 
In view of the fact that this was an experimental type of cell that is to be superseded by an entirely different mounting of the photosensitive surface, the foregoing data are presented merely to illustrate the procedure followed in standardizing, and in testing the performance of selective (photo-electric) radiometers, for use as ultra-violet intensity meters, by means of a nonselective filter radiometer, but they are not to be considered as indicating the performance of a particular make of photo-electric cell. Such variations are to be expected in all selective (photo-electric) radiometers in which the response is not confined to a narrow spectral band, in this case of wave lengths less than $313 \mathrm{~m} \mu$. For a more accurate calibration of such a device, the response should be observed with and without a barium-flint glass filter to eliminate the effect of wave lengths longer than $313 \mathrm{~m} \mu$.

\section{PHYSIOLOGICAL TESTS}

Progress in physiological tests using measured amounts of spectrally pure ("monochromatic") and of spectrally heterogeneous ultra-violet radiation is necessarily slow. Nevertheless such tests will be necessary in order to determine the reliability of an ultraviolet intensity or so-called dosage meter. At the present time there is neither a unit of dosage nor a meter for accurately measuring the amount of ultra-violet radiation used for healing purposes.

The object of the present report is to show the agreement obtained in the erythemic reaction of three sources differing very widely in ultra-violet spectral energy distribution, based upon energy measurements made with the balanced filter radiometer.

These sources are: $(a)$ The sun, in which there is practically no radiation of wave lengths shorter than $290 \mathrm{~m} \mu$, and the intensity at $313 \mathrm{~m} \mu$ is a million times that at $290 \mathrm{~m} \mu ;(b)$ the low voltage, relatively high vapor pressure, mercury arc, in a quartz tube, which has a group of intense emission lines at the wave lengths $248,254,265,280,297$, 302 , and $313 \mathrm{~m} \mu$; and $(c)$ the high voltage, low vapor pressure mercury arc in a quartz tube, in which 93 to 96 per cent of the radiation, of wave lengths less than, and including $313 \mathrm{~m} \mu$, is emitted by the resonance line $254 \mathrm{~m} \mu(2,537 \mathrm{~A})$.

Using spectrally pure radiation, in an erythemic reaction test made on the untanned inner upper arm, during July (high humidity, skin moist) an exposure to the $297 \mathrm{~m} \mu$ line, having a radiant flux of 316 $\mu \mathrm{w} /$ per $\mathrm{cm}^{2}$, produced a minimum perceptible ery thema in 60 seconds on J. M. H. and in a little less than 70 seconds on W. W. C. The total incident energy used was, therefore, about 189,600 and 221,000 ergs, respectively. In another publication (10) it was shown that the amount of energy required to produce a minimum perceptible ery thema on the average untanned inner forearm (wintertime, low humidity, skin dry) using the wave length of maximum ery themic susceptibility (at $297 \mathrm{~m} \mu$ ), is about $500,000 \mathrm{ergs} / \mathrm{cm}^{2}$.

The test on spectrally heterogeneous radiation was made on the same day (July 22, 1931) at the noon hour, when two small areas on the same part of the arm (of W. W. C.) were similarly exposed to the sun (through holes 5 by $15 \mathrm{~mm}$, cut in dark cloth) for 20 and $30 \mathrm{~min}-$ utes, respectively, the ultra-violet radiant flux, of wave lengths less than and including $313 \mathrm{~m} \mu$, being $88 \mu \mathrm{w} / \mathrm{cm}^{2}$. By $5 \mathrm{p} . \mathrm{m}$. the follow-

$$
74280-31-9
$$


ing day the erythema produced by the 20-minute exposure had practically disappeared and the exposed area appeared pigmented. The area that received the 30 -minute exposure was still very red and quite sore to the touch, showing theimportance of a properly timed exposure. Two additional exposures, of 10 and 15 minute duration, on July 23 (ultra-violet radiant flux, $u$. v. $Q,=79 \mu \mathrm{w} / \mathrm{cm}^{2}$ ) failed to produce a definite erythema, though the 15-minute exposure showed slight pigmentation.

Similar exposures were made on J. M. H. (July 27, noon hour, hazy $u$. v. $Q=69 \mu \mathrm{w} / \mathrm{cm},{ }^{2}$ ) for $15,18,21$, and 25 minutes, the 21 minute exposure giving a well-defined minimum erythema.

In the 20-minute exposure on W. W. C. the total energy used in producting an erythema was about 1,056,000 ergs, as compared with 221,000 ergs using homogeneous radiation of wave length $297 \mathrm{~m} \mu$. For J. M. H. the values were 870,000 ergs and 189,600 ergs, respectively. For R. S., on whom the exposures were made on June 3 (solar $u$. v. $Q=78 \mu \mathrm{w} / \mathrm{cm}^{2}$ for 45 minutes; $297 \mathrm{~m} \mu$ line $=395 \mu \mathrm{w} / \mathrm{cm}^{2}$ for 2 minutes) the values were $2,106,000$ ergs and $474,000 \mathrm{ergs}$, respectively.

On this basis the erythemogenic efficiency of Washington midsummer ultra-violet solar radiation, of wave lengths less than and including $313 \mathrm{~m} \mu$ for W. W. C. was, therefore, 20.9 per cent of that of the wave length of maximum erythemic susceptibility; for J. M. H. it was 21.8 per cent; and for R. S. it was 22.5 per cent.

The erythemogenic efficiency of the ultra-violet in midsummer noon-hour sunlight, calculated from the rubescence curve, $R$ (fig. 7 ) is 22 per cent. The agreement between the observed and the calculated efficiency of solar radiation is probably closer than should be expected, in view of the lack of information on the short wave length ultra-violet solar radiation.

It is to be noted that the erythema resulting from the 20-minute exposure on W. W. C. was followed by distinct pigmentation, which made it difficult to decide when the ery thema had ceased. Apparently a shorter exposure to the sun would have produced the desired results, thus increasing the experimentally determined erythemogenic efficiency to a value somewhat higher than 20 per cent. It is to be noted, also, that the 15-minute exposure (total 720,000 ergs) failed to produce an erythema and that the threshold on the inner upper arm of this subject, was about $1,000,000$ ergs, showing the importance of closely timing the exposure, especially when the predominating radiation is of wave lengths 310 to $315 \mathrm{~m} \mu$, in which a small amount of energy added to the threshold is sufficient to produce a burn (10).

In the second series of tests of the physiological application of measured amounts of spectrally heterogeneous ultra-violet radiation in producing a minimum perceptible erythema, the source was a mercury vapor arc, between two tungsten electrodes, located at the top of a V-shaped helical filament of tungsten, in a quartz bulb, which emits a large amount (see Table 5) of erythemogenic radiation of wave lengths less than $290 \mathrm{~m} \mu$, not present in sunlight.

The erythemogenic value (column $d$, Table 5) of the radiation at different wave lengths, is obtained by multiplying the observed spectral intensities (column $b$, Table 5 ) by the erythemic response (10) given in column $c$, Table 5. The ratio of the sum of these components (in relative or absolute units) to the total emitted $(6.42 \div$ 
$23.89=0.269)$ is the erythemogenic efficiency of the spectrally heterogeneous ultra-violet radiation emitted by this particular lamp, operated upon a certain specified voltage.

As shown in Table 3 the ultra-violet intensity, or radiant flux, at $1 \mathrm{~m}$ from this particular lamp, as measured with the balanced thermocouple and exclusion filter method, was $28.0 \mu \mathrm{w} / \mathrm{cm}^{2}$. Hence, the calculated radiant flux of the erythemogenic ultra-violet radiation at $20 \mathrm{~cm}$ from the lamp was $(28.0 \times 25 \times .269)=188 \mu \mathrm{w} / \mathrm{cm}^{2}$.

TABLE 5.-Showing the spectral erythemogenic efficiency of a certain tungsien mercury arc lamp in a quartz bulb

\begin{tabular}{|c|c|c|c|}
\hline $\begin{array}{l}\text { Wave } \\
\text { length } \\
\text { (in } \mathrm{m} \mu)\end{array}$ & $\begin{array}{l}\text { Intensity } \\
\text { at } 1 \mathrm{~m}\end{array}$ & $\begin{array}{l}\text { Erythe- } \\
\text { mic re- } \\
\text { sponse }\end{array}$ & $\begin{array}{l}\text { Erythe- } \\
\text { mogenic } \\
\text { value }\end{array}$ \\
\hline$a$ & b & c & d \\
\hline $\begin{array}{l}313 \\
302 \\
297 \\
289\end{array}$ & $\begin{array}{c}\mu w / \mathrm{cm}^{2} \\
8.94 \\
2.76 \\
2.25 \\
.57\end{array}$ & $\begin{array}{r}0.03 \\
.55 \\
1.00 \\
.19\end{array}$ & $\begin{array}{r}\mu w / \mathrm{cm}^{2} \\
0.27 \\
1.52 \\
2.25 \\
.11\end{array}$ \\
\hline $\begin{array}{l}280 \\
275 \\
270 \\
265\end{array}$ & $\begin{array}{r}1.10 \\
.46 \\
.50 \\
2.78\end{array}$ & $\begin{array}{l}.06 \\
.07 \\
.12 \\
.22\end{array}$ & $\begin{array}{l}.07 \\
.03 \\
.06 \\
.61\end{array}$ \\
\hline $\begin{array}{r}258 \\
254 \\
248 \\
248-230\end{array}$ & $\begin{array}{l}.39 \\
1.80 \\
1.02 \\
1.32\end{array}$ & $\begin{array}{l}.29 \\
.32 \\
.34 \\
.35\end{array}$ & $\begin{array}{l}.11 \\
.58 \\
.35 \\
.46\end{array}$ \\
\hline Total & 23.89 & & 6.42 \\
\hline
\end{tabular}

Exposure to the $297 \mathrm{~m} \mu$ line, having a radiant flux of $395 \mu \mathrm{w} / \mathrm{cm}^{2}$ required between 1.0 and 1.2 minutes to produce a minimum perceptible erythema, on the inside of the upper arm of one of the writers (W. W. C.) hence, to produce a minimum perceptible erythema at a distance of $20 \mathrm{~cm}$ from this lamp the calculated time of exposure was between 2 minutes 7 seconds, and 2 minutes 39 seconds. The actual exposures (five in all) were varied in 10-second intervals ranging from 1 minute 50 seconds to 2 minutes 40 seconds. The resulting erythemas showed that the 2 minutes 40 seconds exposure was decidedly too long, that the 1 minute 50 seconds was underexposed, and that the 2-minute exposure gave practically a miniumm perceptible erythema.

In another test, with the lamp at $25 \mathrm{~cm}$, the observed time of exposure to produce a minimum perceptible erythema was 3 minutes 20 seconds for W. W. C., and between 2 minutes 50 seconds and 3 minutes for J. M. H., which is in good agreement with the calculated time of 3 minutes 23 seconds and 3 minutes 2 seconds, respectively. In this case the erythema test was made directly after the radiometric evaluation of the intensity $\left(387 \times 0.269=104 \mu \mathrm{w} / \mathrm{cm}^{2}\right)$ of erythemogenic radiation from this lamp.

In the third series of erythema tests, using measured amounts of heterogeneous ultra-violet radiation, as compared with the $297 \mathrm{~m} \mu$ line, the source was a so-called "cold quartz lamp" (practically the low vapor pressure Geissler tube discharge in quartz) in which the relative intensities of the lines that could be measured (at the wave 
lengths 254, 297, and $313 \mathrm{~m} \mu$ ) were 865,14 , and 45, respectively. (See Table 5 for a different type of mercury arc.)

The total ultra-violet radiation of wave lengths less than, and including the $313 \mathrm{~m} \mu$ line, at a distance of $25 \mathrm{~cm}$ from the lamp, as determined with the above-described balanced thermopile and filter method (and the observed factor $\mathrm{F}=1.46$ ) was $186 \mu \mathrm{w} / \mathrm{cm}^{2}$.

Irradiation of the inner upper arm (of W. W. C.) for $2,3,4,5$ (3 exposures), and 6 minutes (2 exposures) showed slight discoloration of the skin for the 2 and 3 minute exposures. . The 6-minute exposures were decidedly overexposed, and the minimum exposure appeared to be between 3 and 4 minutes. The minimum exposure for J. M. H. was 3 minutes.

The spectral erythemic response for equal energy, in the region of $254 \mathrm{~m} \mu$ is not well established (10). The average value of the various observers is about 45 per cent as compared with 100 per cent at $297 \mathrm{~m} \mu$. On this basis the calculated time of exposure to produce a minimum perceptible erythema would have been 3.4 minutes, as compared with observed values of 3 to 4 minutes. Considering the possible errors in the radiation measurements, on this type of lamp and the uncertainty in the spectral erythemic response curve at wave lengths less than and including $254 \mathrm{~m} \mu$, the observed and the calculated times of exposure are in good agreement.

An important result of this experiment is that an exposure of two to three times the threshold dosage produced only an intense superficial reddening of the skin, whereas a slight overexposure to the longer wave lengths (at $313 \mathrm{~m} \mu$ ) in the sun produced a painful burn (10), which phenomenon was observed long ago, but only in recent times is being taken into consideration.

In view of the complex correlation between the spectral energy distribution of the source and the spectral erythemic response curve (which is subject to misinterpretation of the effect produced by the short wave lengths), the agreement between the observed time of exposure, using measured amounts of spectrally heterogeneous ultraviolet radiation from three sources differing very markedly in spectral energy distribution, and the calculated time of exposure, based upon the total energy required to produce an erythema by means of the $297 \mathrm{~m} \mu$ line (the wave length of maximum ery themic susceptibility), is as close as can be expected.

The results of these tests indicate how closely the exposures must be timed in order to obtain consistent results. According to earlier observers a close agreement in erythema tests is not possible. It is to be noted, however, that their observations were not made with accurately measured amounts of spectrally heterogeneous ultraviolet radiation and the effects compared with that of the $297 \mathrm{~m} \mu$ line. Evidently, tests on a group of observers will be desirable to establish an average.

It is to be noted (10) that the erythemic reaction of the human skin, on short exposure to the very short wave lengths (240 to 280 $\mathrm{m} \mu$ ) of ultra-violet radiation, rises to a maximum and disappears again in the course of a few hours, whereas a similar number of hours elapses before the erythema produced by the longer wave lengths $(313 \mathrm{~m} \mu)$ becomes at all visible and about 5 hours more are required for the reddening to attain a maximum, after which (if pigmentation has not started) some 15 to 20 hours may elpase before the ery thema 
disappears. But even after the erythema has apparently disappeared it can be restored by wiping the surface with alcohol.

Hence, it can hardly be expected that there will always be an exact agreement between the erythemic efficiency of the wave length $(297 \mathrm{~m} \mu)$ of maximum susceptibility and the efficiency derived from an integration of the rubescence curve $R$ (fig. 7), obtained from the spectral energy curve of the sun, or from an artificial source.

As just noted the total ultra-violet solar energy required to produce a mild erythema may be somewhat larger (exposure longer) than the calculated value; and in artificial sources, emitting considerable ultra-violet of wave lengths less than $270 \mathrm{~m} \mu$, the time of exposure may be found to be somewhat shorter than the calculated value. However, it will serve as a guide in determining the safe dosage exposure, which is the purpose of the whole procedure (10).

\section{SUMIMARY}

The present paper is a further contribution (see RP318) to the investigation of filter radiometry, with special reference to the quantitative measurement of the component of ultra-violet radiation of wave lengths less than $313 \mathrm{~m} \mu$ in sunlight and in artificial sources, which biologists recognize as of special importance in the prevention and cure of rickets.

The apparatus used was a balanced radiometer, consisting of a thermocouple in which the two receivers are simultaneously exposed to radiation, under which conditions practically no thermoelectric current flows through the galvanometer. A $1 \mathrm{~cm}$ cell of water or of crystal quartz was used continuously over the thermocouple receivers.

On covering one receiver with a filter that excludes the ultra-violet which it is desired to evaluate and the other receiver with a window that freely transmits these ultra-violet rays, and exactly balances the transmission losses of the exclusion filter, throughout the remaining part of the spectrum, the galvanometer deflection obtained on exposure of the two thermocouple receivers through this combination of filters is a direct measurement of the ultra-violet emitted by the source under investigation. In order to evaluate the ultraviolet of wave lengths less than $313 \mathrm{~m} \mu$, it is necessary to know the relative spectral energy distribution of the source for wave lengths less than $400 \mathrm{~m} \mu$.

The ultra-violet exclusion filter was a barium flint glass and the balancing filter was of crystal quartz or Corex G980A glass, depending upon the source of radiation. The lack of complete balance of long wave-length radiation was determined by covering both receivers with a plate of Noviol-A glass, which is opaque to radiation of wave lengths less than $400 \mathrm{~m} \mu$, the long. wave length endpoint of the barium fiint exclusion filter.

Using two arrangements of $(a)$ the balanced pair of thermocouple receivers with a single exclusion filter method, and $(b)$ a single thermocouple receiver with two exclusion filters (three methods in all), and (c) using two methods of calibrating the radiation sensitivity of the thermocouple receivers in absolute units, closely agreeing measurements were made showing that the average amount of ultra-violet radiation of wave lengths less than and including $313 \mathrm{~m} \mu$, for midlatitude sea level stations, during the clearest weather, during midday 
in midsummer, amounts to about $90 \mu \mathrm{w} / \mathrm{cm}^{2}$, decreasing to about $20 \mu \mathrm{w}$ on the clearest days in midwinter.

An experimental procedure is described for testing the performance and for standardizing photo-electric cells for use as ultra-violet intensity (so-called dosage) meters.

An experimental procedure is described for using measured amounts of spectrally pure ("monochromatic") ultra-violet radiation in physiological tests, such as, for example, the amount of ultra-violet energy required to produce a minimum perceptible erythema on the untanned human skin. Data are given showing that the erythemogenic efficiency of Washington midsummer ultra-violet solar radiation is only about 21 per cent that of the wave length $(297 \mathrm{~m} \mu)$ of maximum erythemic susceptibility. Using the spectral erythemic response curve, observed by the writers, the calculated ery themogenic efficiency is 22 per cent, which is as close an agreement as can be expected, in view of the uncertainty in the ultra-violet solar spectral energy curve upon which the calculations must be based.

Using an artificial source of radiation in which the ultra-violet spectral energy distribution and the total erythemogenic ultra-violet radiation could be accurately measured, the observed time of exposure to the total radiation from the lamp, required to produce a minimum perceptible erythema, was in good agreement with the time calculated from observations using the wave length $(297 \mathrm{~m} \mu$ ) of maximum erythemic susceptibility.

\section{BIBLIOGRAPHY}

1. Measurements of Extreme Ultra-Violet Solar Radiation by a Filter Method, W. W. Coblentz, R. Stair, and J. M. Hogue, B. S. Jour. Research, vol. 6 (RP318), p. 951; 1931. This paper gives an extensive bibliography of previous contributions to the general subject of instruments and methods of radiometry.

2. Spectral Distribution of Energy Radiated from a New Type Tungsten Mercury Arc., B. T. Barnes, Phys. Rev., vol. 36, p. 1468; 1930. Spectral Transmission of Quartz-Fluorite Monochromators, W. E. Forsythe and B. T. Barnes, Rev. Sci. Inst., vol. 1, p. 569; 1930; M. Rosenmüller, Ann. der Phys., (4), vol. 29 , p. $355 ; 1909$.

3. Measurements on Standards of Radiation in Absolute Value, W. W. Coblentz, B. S. Bull. No. 227, vol. 11 , p. $87 ; 1914$.

4. Sensitivity and Magnetic Shielding Tests of Thomson Galvanometers for Use in Radiometry, W. W. Coblentz, B. S. Bull. No. 282, vol. 13, p. 423; 1916.

5. Disintegration of Metal Surfaces by Ultra-Violet Radiation, W. W. Coblentz and C. W. Hughes, Sci., vol. 60, p. 64; B. S. Sci. Papers vol. 19 (S493), p. 577; 1924; W. W. Coblentz and R. Stair, B. S. Jour. Research, vol. 4 ( $\mathrm{RP} 141)$, p. $189 ; 1930$. This is a problem that must be considered in connection with the use of photo-electric cells.

6. Various Modifications of Bismuth Silver Thermopiles Having a continuous Absorbing Surface, W. W. Coblentz, B. S. Bull. No. 229, p. 131; 1914. Another arrangement to be tested consists of two thin blackened metal strips, in front of the thermocouple receivers, which can be calibrated in absolute measure by electric heating, as in the Angström pyrheliometer.

7. Measures of The Radiation of 'The Solar Corona, H. T. Stetson and W. W. Coblentz, Astrophys. J. vol. 62, p. 128; 1925. A photograph of the balanced thermopile is illustrated in Figure 1 of this publication.

8. Data On Ultra-Violet Solar Radiation and the Solarization of Window Materials, W. W. Coblentz and R. Stair, B. S. Jour. Research, vol. 3, (RP113) p. $629 ; 1929$.

9. A Radiometric Investigation of the Germicidal Action of Ultra-Violet Radiation, W. W. Coblentz and H. R. Fulton, B. S. Sci. Papers, vol. 19, (S495), p. $641 ; 1924$. Kreusler, Ann. der Physik, (4), vol. 6, p. 412; 1901. 
10. The Spectral Erythemic Reaction of the Human Skin to Ultra-Violet Radiation, W. W. Coblentz, R. Stair and J. M. Hogue, Proc. Nat. Acad. Sci., vol. 17, p. $401 ; 1931$.

11. An Uitra-Violet Light Meter, H. C. Rentschler, Trans. Amer. Inst. Elect. Eng., New York Convention, January 27 to 31, 1930.

12. The Ultra-Violet and Visible Transmission of Eye-Protective Glasses, K. S. Gibson and H. J. McNicholas, BS. Tech. Papers No. 119, issued June 7, 1919. The standard samples complying with the present specifications were prepared by Dr. H. P. Gage, Corning Glass Works Research Laboratory.

13. Constants of Spectral Radiation of a Uniformly Heated Inclosure or socalled Black Body, I, W. W. Coblentz, B. S. Bull. No. 204, vol. 10, p. 44; 1913. This paper describes the method commonly used for reducing the observed data from prismatic to a normal spectrum.

WASHington, JuLy 30, 1931. 